than those receiving not anticonvulsants, perhaps accounting for the greatly increased incidence of rejection observed.

It seems logical to provide maximum immunosuppression at the time when the immune response is most active and when transplant rejection may be most likely. Some of the drugs could be taken at night to avoid the low morning levels of immunosuppression which probably occur with most regimens. Suitable studies are needed, both in the experimental laboratory and in the transplant unit, to test whether rejection would then be less likely or less severe.

Our investigations were initiated to determine whether rhythms of physiological or pathological activity need to be considered when treating patients with renal transplantation. Analysis of the results provides some support for the hypothesis that there is a circadian rhythm in allograft rejection. Data collected prospectively are needed to confirm this and provide information relevant to planning treatment. Immune responses are important in many other conditions, and our observations suggest that circadian variations should be considered when treating them. Seven-day rhythms of renal allograft rejection may occur, ${ }^{16}$ and preliminary analysis of our results supports this suggestion. Thought should be given to the most appropriate times to administer treatment to achieve the maximum effect and minimum toxicity. ${ }^{17}$ More research is needed into the relevance of circadian and other rhythms to the diagnosis, management, and treatment of disease.

We are grateful to the many members of the hospital staff who shared in the care of these patients, especially those in the department of clinical chemistry responsible for the plasma creatinine analyses.
The patients were under the care of Mr R W Blamey, Dr R P Burden, and $\operatorname{Dr} M S$ Knapp. The project was supported by grants from the National Kidney Research Fund and the Trent Regional Health Authority.

The results were presented at a symposium on chronopharmacology in Tallahassee, Florida, in February 1978, and at the International Society of Nephrology in Montreal in June 1978.

\section{References}

${ }^{1}$ Ratte, J, et al, Surgery, 1973, 73, 102.

Pownall, R, and Knapp, M S, Clinical Science and Molecular Medicine, 1978, 54, 447.

${ }^{3}$ Cove-Smith, J R, et al, British Medical fournal, 1978, 2, 253.

${ }^{4} \mathrm{Knapp}, \mathrm{M}$ S, Kowanko, I C, and Pownall, R. In preparation.

${ }^{5}$ Knapp, M S, et al, Lancet, 1977, 2, 1183.

6 Koukkari, W L, et al, Chronobiologia, 1974, 1, 281.

${ }^{7}$ Di Raimondo, V C, and Forsham, P H, American fournal of Medicine, 1956, 21, 321.

${ }^{8}$ Reinberg, A, Chronobiologia, 1976, 3, 151.

${ }^{9}$ Focan, C, Lancet, 1976, 2, 638.

10 Sheving, L E, Mayersbach, H, and Pauly, J E, Fournal of European Toxicology, 1974, 7, 203.

${ }^{11}$ Demster, W J, British fournal of Experimental Pathology, 1970, 51, 149.

${ }^{12}$ Lewis, G P, and Mangham, B A, British fournal of Pharmacology. In press.

13 Wood, R F M, and Bell, P R F, in Immunology for Surgeons, ed J E Castro. Lancaster, UK, MTP Press Ltd, 1977.

14 Wassner, S J, et al, Fournal of Pediatrics, 1976, 77, 134

15 Sells, R A, Transplantation. In press.

$16 \mathrm{De}$ Vecchi, A, et al, in Proceedings of International Symposium on Chronopharmacology, ed C Walker. In press.

17 British Medical fournal, 1978, 1, 1376.

\title{
Metabolic consequences of atenolol and propranolol in treatment of essential hypertension
}

\author{
J L DAY， N SIMPSON，J METCALFE， R L PAGE
}

British Medical fournal, 1979, 1, 77-80

\section{Summary and conclusions}

A six-month study of triglyceride, cholesterol, free fatty acid (FFA), glucose, insulin, growth hormone, and glucagon concentrations was carried out in asymptomatic hypertensive normal-weight men randomly allocated to treatment with atenolol or propranolol. A highly significant increase in the basal plasma triglyceride concentration was observed in propranolol-treated patients after three and six months' treatment, with a smaller but significant increase in atenolol-treated subjects after six months' treatment. The changes in triglyceride concentration could not be ascribed to variations in plasma insulin, growth hormone, or glucagon concentrations. Basal FFA concentrations were reduced during the first three months of treatment in both groups but returned to pretreatment levels after six months. Plasma cholesterol concentrations were unchanged by either agent.

Department of Medicine, Ipswich Hospital, Suffolk IP4 5PD

J L DAY, MD, MRCP, consultant physician

N SIMPSON, MB, MRCP, clinical assistant

J METCALFE, BSC, biochemist

R L PAGE, DM, MRCP, senior registrar (present appointment: senior registrar, Addenbrooke's Hospital, Cambridge)
Propranolol had a greater effect on triglyceride concentrations than atenolol, but probably all beta-blocking agents have similar effects of different magnitudes. These effects should be investigated further in view of the postulated association between plasma triglyceride concentrations and cardiovascular disease.

\section{Introduction}

Intravenously administered $\beta$-adrenergic antagonists (betablockers) may significantly alter plasma insulin, free fatty acid (FFA), and possibly glucose concentrations in man. ${ }^{12}$ The consequences of long-term treatment with such agents have not been adequately studied, ${ }^{3}$ however, and reports have given conflicting results. Failure to show major metabolic changes may in some instances be due to the study of heterogeneous groups of subjects ${ }^{5}$ or of patients with angina or recent myocardial infarction, ${ }^{6-8}$ in whom glucose tolerance and plasma lipid concentrations may be influenced by changes in ambulation, irrespective of any medication that they might receive. More recently Waal-Manning and Simpson ${ }^{9}$ reported an increase in the plasma triglyceride concentration during treatment with metoprolol (a selective beta-blocker), while Newman ${ }^{10}$ reported a significant fall in basal FFA concentrations after short-term treatment with acebutolol (a selective beta-blocker) and propranolol (an unselective beta-blocker) but not with metoprolol.

We undertook this study to determine whether atenolol (a relatively selective beta-blocker) or propranolol given by mouth over 
six months to asymptomatic patients with essential hypertension caused significant changes in lipid or glucose metabolism and whether these could be related to alterations in plasma insulin or glucagon concentrations. The study was carefully conducted to ensure that observed changes in these various indices were the result of treatment alone.

\section{Patients and methods}

Forty-nine men with newly diagnosed essential hypertension entered the study. All had had an initial supine blood pressure above $150 \mathrm{~mm} \mathrm{Hg}$ systolic and $100 \mathrm{~mm} \mathrm{Hg}$ diastolic recorded after 10 minutes at rest on at least two occasions. All were within $10^{\circ}{ }_{0}$ of their ideal body weight and aged under 60 years (table).

We excluded from the study patients who gave a previous history of cardiovascular disease, major gastrointestinal surgery, renal impairment, pancreatic disease, diabetes mellitus, or other endocrine disease. Patients were also excluded if they had received treatment for hypertension, obesity, or lipid abnormalities; if they had taken any medication within the previous month; or if they had any abnormalities in blood count, liver function tests, blood urea concentration, creatinine clearance, or intravenous pyelogram.

Patients entering the study were investigated before and after three months' and six months' treatment with propranolol or atenolol, to which they were randomly allocated. They maintained their normal diet throughout. The dosage of propranolol (40-160 $\mathrm{mg}$ three times daily) or atenolol (50-100 mg twice daily) was adjusted to achieve diastolic blood pressures below $100 \mathrm{~mm} \mathrm{Hg}$. The tests were conducted in the laboratory at $830 \mathrm{am}$ after an overnight fast, the patients having taken their usual morning medication one hour beforehand and having refrained from smoking for 12 hours before the test. Blood samples were withdrawn via an indwelling intravenous cannula kept patent with isotonic saline, the first basal blood sample being obtained after 30 minutes' recumbency. Further blood samples were obtained at 15 , $30,45,60,90,120$, and 180 minutes after a $100 \mathrm{~g}$ oral glucose load. All samples were analysed for glucose, FFA, insulin, and glucagon (radioimmunoassay using $30 \mathrm{~K}$ antiserum). Basal samples were analysed for triglyceride and cholesterol.

We used standard parametric $t$ tests and correlation analyses for the results in the propranolol and atenolol groups, and non-parametric Wilcoxon and Spearman rank coefficients for those in the total group.

\section{Results}

Thirty patients completed the study ( 16 receiving propranolol and 14 atenolol). Fifteen patients were withdrawn because they needed additional hypotensive treatment or developed side effects, and four patients failed to attend for the second or third assessment. There were no significant differences in the pretreatment characteristics of the groups (table). Similar falls in blood pressure and resting pulse rate occurred in both groups after three and six months' treatment, and body weights remained constant.

The patients as a whole showed a highly significant increase in mean basal plasma triglyceride concentration after both treatment periods, the increase being more pronounced in those who received propranolol (table). Basal FFA concentrations were significantly reduced in both groups after three months' treatment, as were FFA concentrations at 15 and 30 minutes after glucose ingestion (fig 1), but they returned to near
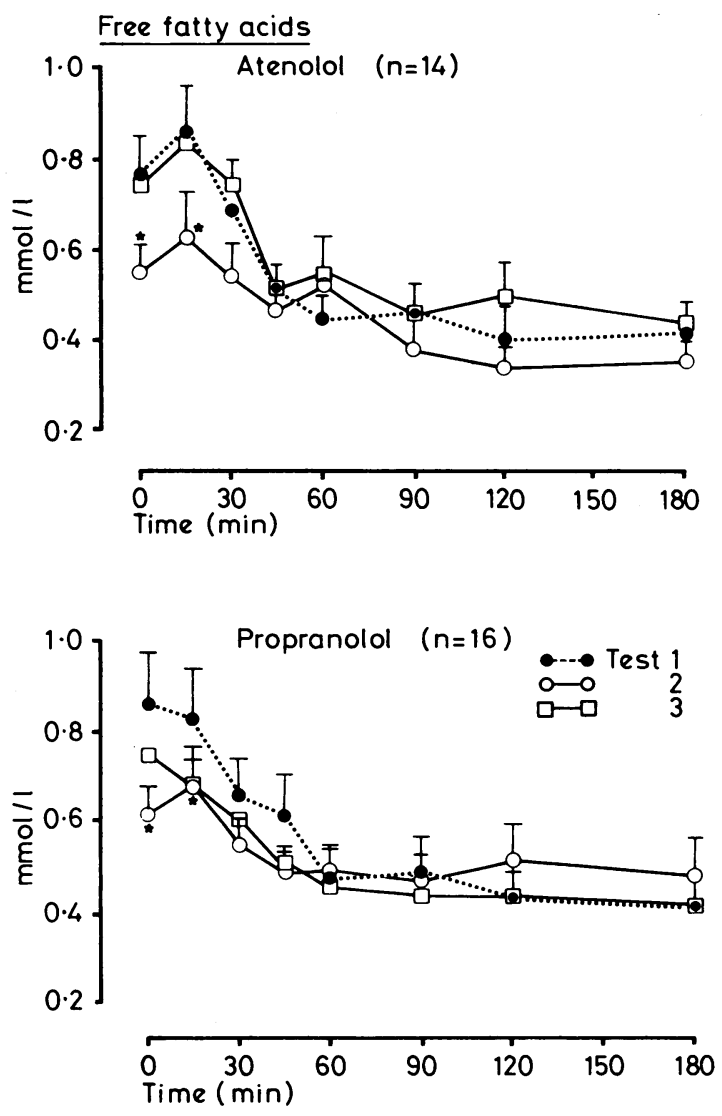

FIG 1-Mean ( \pm SE of mean) plasma free fatty acid concentrations after oral glucose before (test 1) and after three months' (test 2) and six months' (test 3) treatment with atenolol or propranolol.

${ }^{*} \mathrm{P}<0.05$ : significance of difference from test 1 .

Conversion: SI to traditional units-Free fatty acid:

$1 \mathrm{mmol} / \mathrm{l}=1 \mathrm{mEq} / 1$.

pretreatment levels in both groups after six months' treatment. There were no significant changes in basal plasma cholesterol concentration after three or six months' treatment with either agent.

No significant changes were observed in basal concentrations, individual post-glucose concentrations, or mean concentrations of insulin or glucagon with either treatment regimen (fig 2). No rise in plasma growth hormone occurred.

Basal glucose concentrations were not influenced by treatment with either agent (fig 3) but glucose concentrations 45 and 60 minutes after glucose ingestion were significantly reduced in the propranolol-treated group. Overall, mean glucose coricentrations were significantly reduced after three and six months' treatment with propranolol $(P<0.025)$. Increment of insulin per unit of glucose was also significantly increased after three and six months' treatment with propranolol $(P<0.05)$ but not with atenolol.

We attempted to correlate the change in triglyceride concentration

Mean ( $\pm S E$ of mean) triglyceride and cholesterol concentrations, blood pressure, and resting pulse rate before and after three and six months' treatment with propranolol or atenolol

\begin{tabular}{|c|c|c|c|c|c|c|c|c|c|c|}
\hline & \multicolumn{4}{|c|}{ All patients $(n=30)$} & \multicolumn{3}{|c|}{ Propranolol $(n=16)$} & \multicolumn{3}{|c|}{ Atenolol $(n=14)$} \\
\hline & Before & & $\begin{array}{l}\text { er three } \\
\text { onths' } \\
\text { atment }\end{array}$ & $\begin{array}{l}\text { After six } \\
\text { months' } \\
\text { treatment }\end{array}$ & Before & $\begin{array}{c}\text { After three } \\
\text { months' } \\
\text { treatment }\end{array}$ & $\begin{array}{l}\text { After six } \\
\text { months' } \\
\text { treatment }\end{array}$ & Before & $\begin{array}{c}\text { After three } \\
\text { months' } \\
\text { treatment }\end{array}$ & $\begin{array}{c}\text { After six } \\
\text { months' } \\
\text { treatment }\end{array}$ \\
\hline \multirow{2}{*}{$\begin{array}{l}\text { Mean age (years) } \\
\text { Weight (kg) } \\
\text { Triglyceride (mmol/l) } \\
\text { Cholesterol (mmol/l) } \\
\text { Blood pressure (mm Hg): } \\
\text { Systolic } \\
\text { Diastolic } \\
\text { Resting pulse (beats/min) }\end{array}$} & $\begin{array}{c}45 \\
78 \cdot 8 \pm 1.9 \\
1.4 \pm 0.1 \\
6.7 \pm 0.3\end{array}$ & $\begin{array}{r}78 \cdot 8 \\
1.9 \\
6.5\end{array}$ & $\begin{array}{l} \pm 1.9 \\
\pm 0.2 \\
\pm 0.3\end{array}$ & $\begin{array}{rl}79.3 & 1.9 \\
2.04 & =0.2^{* * * *} \\
7.0 & \pm 0.3\end{array}$ & $\begin{array}{c}46 \\
77 \cdot 9 \pm 2 \cdot 9 \\
1 \cdot 4 \pm 0 \cdot 2 \\
6 \cdot 5 \pm 0 \cdot 4\end{array}$ & $\begin{array}{r}77 \cdot 9 \pm 3 \cdot 0 \\
2 \cdot 2 \pm 0.3 \\
6 \cdot 4 \div 0 \cdot 3\end{array}$ & $\begin{array}{l}78.9 \pm 3.0 \\
2.31 \pm 0.3 * * \\
6.9 \pm 0.3\end{array}$ & $\begin{array}{c}79.8 \pm 2.3 \\
1.39 \pm 0.2 \\
6.9 \pm 0.6\end{array}$ & $\begin{array}{c}80.0 \pm 3.0 \\
1.64 \pm 0.2 \\
6.6 \pm 0.4\end{array}$ & $\begin{array}{c}79.9 \pm 1.9 \\
1.73 \pm 0.2^{*} \\
7.01 \pm 0.5\end{array}$ \\
\hline & $\begin{array}{r}169 \cdot 8 \pm 3 \cdot 0 \\
108 \cdot 2 \pm 1 \cdot 2 \\
69 \cdot 7 \pm 2 \cdot 7\end{array}$ & $\begin{array}{c}135 \cdot 2 \\
86 \cdot 5 \\
58 \cdot 15\end{array}$ & $\begin{array}{l} \pm 2 \cdot 7^{* *} \\
\pm 1 \cdot 5^{* *} \\
\pm 1 \cdot 4\end{array}$ & $\begin{array}{ll}* 132.0 & \pm 2.1^{* * *} \\
85.5 & \pm 1.4 \\
61.2 & \pm 1.5^{* * *}\end{array}$ & $\begin{array}{r}168.9 \pm 3.9 \\
108.1 \pm 1.5 \\
69.6 \pm 3.9\end{array}$ & $\begin{array}{c}133.5=3 \cdot 6 * * * \\
84.9=1.9 * * * \\
58.8 \pm 2 \cdot 2\end{array}$ & $\begin{array}{rr}132 \cdot 4 & \pm 3 \cdot 0^{* * *} \\
86.9 & \pm 2 \cdot 1^{* * *} \\
63.9 & \pm 2 \cdot 1^{* * *}\end{array}$ & $\begin{aligned} 170 \cdot 7 & \pm 4 \cdot 7 \\
108.2 & \pm 1.9 \\
66.8 & \pm 3.86\end{aligned}$ & $\begin{aligned} 137 \cdot 0 & \pm 4 \cdot 1^{* * *} \\
88 \cdot 1 & \pm 2 \cdot 4^{* * *} \\
57.5 & \pm 1.9\end{aligned}$ & $\begin{aligned} 131.5 & \pm 3 \cdot 1^{* * *} \\
83.9 & \pm 1 \cdot 7^{* * *} \\
58.1 & \pm 1 \cdot 9^{* * *}\end{aligned}$ \\
\hline
\end{tabular}




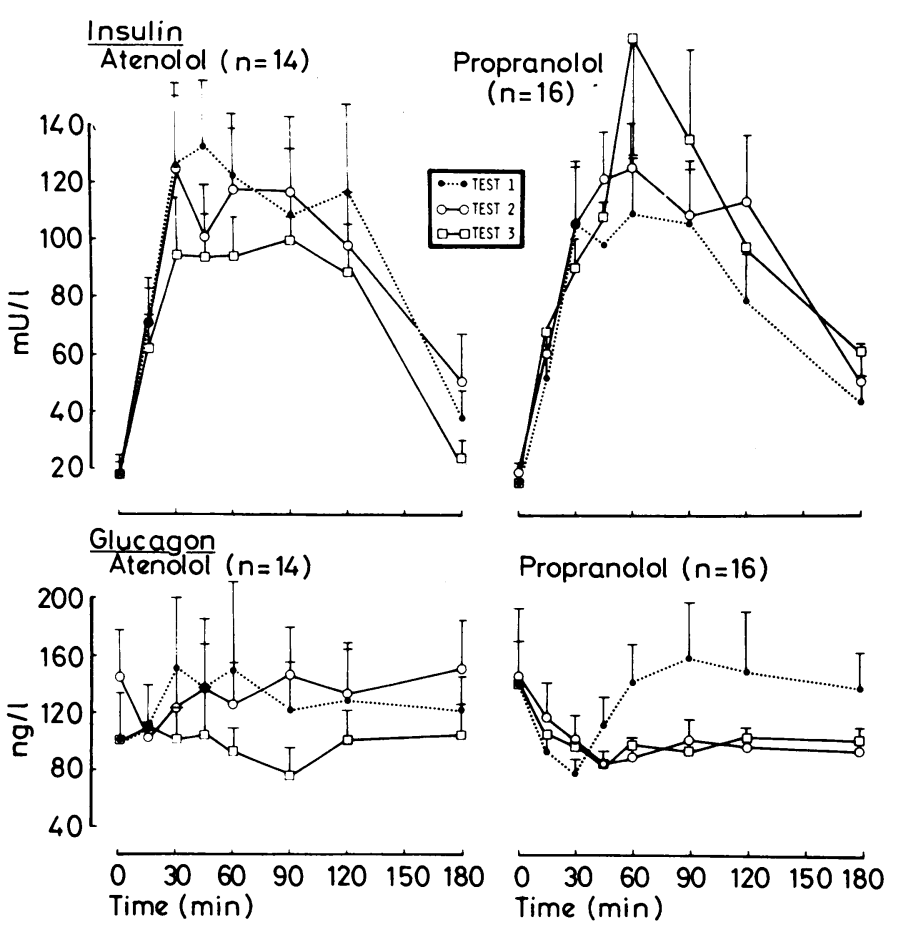

FIG 2-Mean ( \pm SE of mean) plasma insulin and glucagon concentrations after oral glucose before (test 1) and after three (test 2) and six (test 3) months' treatment with atenolol or propranolol.
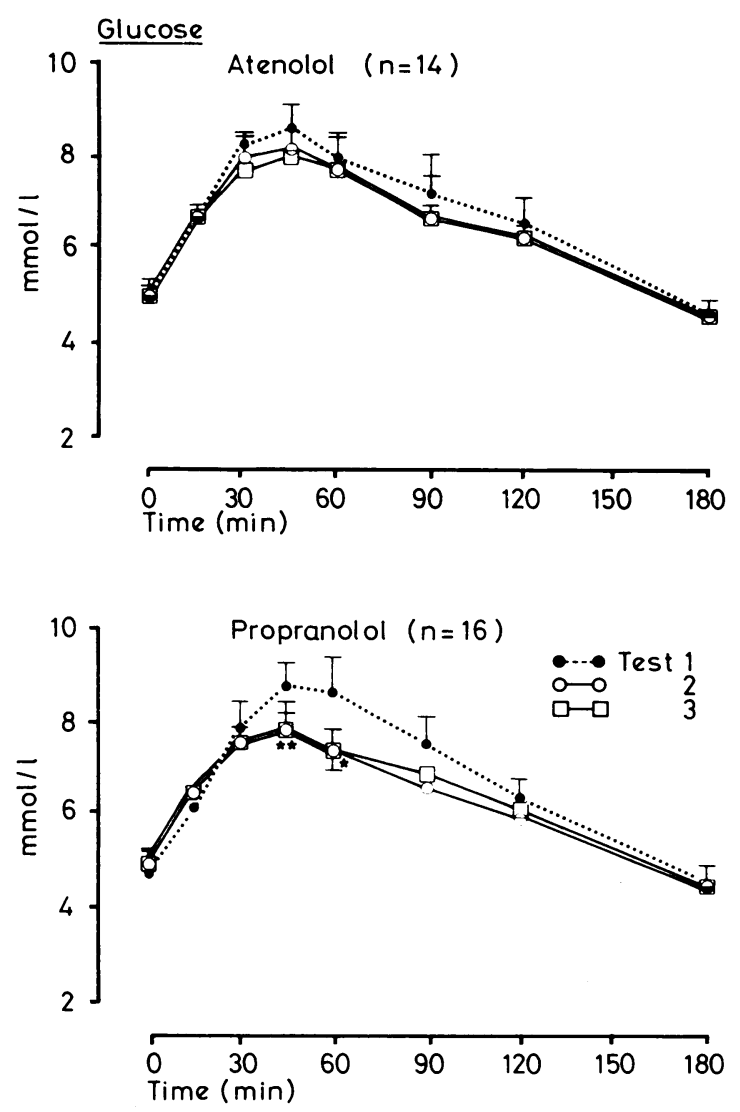

FIG 3-Mean ( \pm SE of mean) plasma glucose concentrations after oral glucose before (test 1 ) and after three (test 2) and six (test 3) months' treatment with atenolol or propranolol.

${ }^{*} \mathrm{P}<0.05 ;{ }^{* *} \mathrm{P}<0.001$, significance of difference from test 1 .

Conversion: SI to traditional units-Plasma glucose: $1 \mathrm{mmol} / \mathrm{l} \approx 18 \mathrm{mg} / 100 \mathrm{ml}$. with changes in other indices but found no significant correlations. In particular there was no correlation between changes in triglyceride concentration and individual changes in weight, basal or mean insulin concentration, insulin to glucose ratio, glucose concentration, basal cholesterol concentration, or blood pressure.

\section{Discussion}

The most significant metabolic change observed in this study was the pronounced increase in the basal plasma triglyceride concentration in the patients treated with propranolol for three and six months. Atenolol treatment resulted in a similar trend, though the increase was smaller. These observations must be attributed to the treatment used, as other factors known to affect basal triglyceride concentrations, such as alterations in diet, weight, posture, and season, were excluded. Waal-Manning and Simpson $^{9}$ recently showed similar increases in the plasma triglyceride concentration in hypertensive patients treated with metoprolol but other workers ${ }^{11}$ have failed to show such changes, and these discrepancies require explanation.

Triglyceride concentrations fall progressively with increased exertion and during recovery from myocardial infarction. ${ }^{12} 13$ Thus increases induced by beta-blockers may be obscured in studies of patients after myocardial infarction ${ }^{6} 7$ or cerebrovascular accidents. ${ }^{8}$ Lloyd-Mostyn et $a l^{4}$ were unable to detect any changes in plasma triglyceride or cholesterol concentrations in propranolol- or practolol-treated hyperlipidaemic patients, but their study was of short duration and the values obtained on sequential testing varied widely. Furthermore, the influence of propranolol on postalimentary lipaemia may differ in normal and hyperlipidaemic subjects. ${ }^{5}$

The significantly reduced basal plasma FFA concentrations after treatment with either propranolol or atenolol accord with the known antilipolytic effect of $\beta$-adrenergic agents in vitro and confirm the observations of Newman ${ }^{10}$ using acebutolol and propranolol. It appears that this is a temporary phenomenon, however, since the concentrations had returned to pretreatment values after six months' treatment.

In the absence of significant changes in the insulin concentration the fall in post-ingestion glucose concentrations after propranolol treatment requires explanation. Reduction in muscle lactate production ${ }^{14}$ might reduce basal glucose concentrations but not post-ingestion concentrations as observed in this study. Increased peripheral extraction before sampling due to the vasoconstrictive action of $\beta$-adrenergic agents might be an alternative. The failure to detect changes in plasma insulin or glucagon concentrations suggests that $\beta$-adrenergic receptors do not have an important role in basal or post-glucose secretion of these hormones.

The cause of the rise in plasma triglyceride concentration must remain speculative. The increase cannot be attributed in these studies to insulin-induced synthesis, increased lipolysis provoked by glucagon or growth hormone, or an increase in available substrate (FFA concentrations decreased); thus whether it is due to increased synthesis or decreased metabolism remains to be determined. Barboriak and Friedberg ${ }^{5}$ suggested an increased postalimentary lipaemia in propranolol-treated hyperlipidaemic subjects, and in the study of Tanaka $e^{2} \mathrm{al}^{8}$ a fall in post-heparin lipolytic activity was observed as well as a redistribution within the lipoprotein fractions. In a recent study of lipid concentrations during treatment of hypertension with a thiazide diuretic similar increases in triglyceride concentration were observed and correlated with the fall in blood pressure. ${ }^{15}$ Thus the increase in plasma triglyceride concentration may possibly result from a fall in blood pressure and be unrelated to the therapeutic agents used, although in this study we were unable to show any such correlation.

Our observations suggest that atenolol treatment has a less pronounced effect on the plasma triglyceride concentration than propranolol. Whereas in the propranolol-treated group the mean plasma triglyceride concentrations rose to a level above the 
accepted normal range, this was not so in the atenolol-treated group. It seems likely from the data so far that all beta-blocking agents have similar effects, though the magnitude of such effects could depend on the so-called selectivity of the drug used. That differences not only of magnitude but possibly also of direction might occur is suggested by the observations of Newman ${ }^{10}$ that metoprolol failed to lower FFA concentrations compared with acebutolol and propranolol, and by those of Keene, ${ }^{16}$ who showed a rise in FFA concentrations in oxprenolol-treated diabetics. Thus the effects of different beta-blockers on various metabolic variables may be totally unrelated to their selectivity. ${ }^{3}$ Whatever the mechanism of action it would seem prudent to investigate all beta-blockers and other hypotensive agents for their effect on plasma triglyceride concentrations in view of the postulated association between these concentrations and the development of cardiovascular disease.

We thank ICI and Stuart Pharmaceuticals for financial support, and Mrs H Humphreys and Mrs A Osborne for technical help.

\section{References}

${ }^{1}$ Fain, J N, Pharmacological Revues, 1973, 25, 67.

${ }^{2}$ Robertson, R P, and Porte, D, jun, Diabetes, 1973, 22, 1.

${ }^{3}$ Day, J L, Metabolism, 1975, 24, 987.

${ }^{4}$ Lloyd-Mostyn, R H, et al, Atherosclerosis, 1971, 14, 283.

${ }^{5}$ Barboriak, J J, and Friedberg, H D, Atherosclerosis, 1973, 17, 31.

${ }^{6}$ Muller, H, Barthels, F, and Kluthe, R, Medizinische Klinik, 1973, 68, 634.

${ }^{7}$ Ghosh, P, Cochrane, A M G, and de Bono, D, Lancet, 1975, 1, 9.

${ }^{8}$ Tanaka, N, et al, Metabolism, 1976, 25, 1071.

${ }^{9}$ Waal-Manning, H J, and Simpson, F O, British Medical fournal, 1977, 2 , 705.

${ }^{10}$ Newman, R J, British Medical fournal, 1977, 2, 601.

${ }^{11}$ Nilsson, A, Hansson, B G, and Hokfelt, B, British Medical Fournal, 1977, 2, 126.

12 Bjorntorp, P, et al, Metabolism, 1970, 19, 631.

${ }_{13}$ Day, J L, Page, R L, and Metcalfe, J. In preparation.

14 Vizi, E D, Pagatsa, G, and Kaldor, A, Fournal of Pharmacy and Pharmacology, 1965, 17, 805.

${ }^{15}$ Ames, R P, and Hill, P, American fournal of Medicine, 1976, 61, 748.

${ }^{16}$ Keene, $\mathrm{H}$, personal communication.

(Accepted 26 October 1978)

\title{
Bacteriological quality control in human milk-banking
}

\author{
A LUCAS, C D ROBERTS
}

British Medical fournal, 1979, 1, 80-82

\section{Summary and conclusions}

The bacteriological quality of pooled human milk donated to the Oxford milk bank was analysed and the effects on bacteriology of sterilisation of the milkcollecting vessels in the home with hypochlorite solution and of Holder pasteurisation in a purpose-built humanmilk pasteuriser were studied. Collecting milk in hypochlorite-sterilised vessels resulted in a significantly lower bacterial count of both pathogens and species of unlikely pathogenicity before pasteurisation and significantly increased the chance of pasteurisation giving a sterile product. Potentially pathogenic organisms grown in untreated milk were Escherichia coli, Staphylococcus aureus, and group $B$-haemolytic streptococci. Seven species of organisms of unlikely pathogenicity were also identified. Pasteurisation eliminated all potential pathogens from milk but did not reliably remove any of the species of unlikely pathogens.

Banked human milk may be contaminated with bacteria which are known to be capable of producing lipases, proteases, and decarboxylases. Accurate pasteurisation, together with attention to the sterility of the collecting vessels, results in a bacteriologically safe product that retains many of the protective properties of raw milk.

\footnotetext{
University Department of Paediatrics, John Radcliffe Hospital, Oxford OX3 9DU

A LUCAS, MRCP, research fellow

UK Research and Development Laboratories, Vick International, Slough

C D ROBERTS, PHD, clinical trials manager
}

\section{Introduction}

Despite the re-emergence of human milk banks to provide milk for infants of low birth weight and sick infants in special-care baby units, optimal procedures in human milk-banking have not been defined. One unresolved problem is preserving the heatlabile antimicrobial components in human milk while making the milk bacteriologically safe for high-risk neonates. Accurate pasteurisation of milk results in relatively little damage to some of the major humoral protective factors in milk. ${ }^{1-3}$

We examined the bacteriological quality of milk donated to the Oxford milk bank before and after pasteurisation in a purpose-built human-milk pasteuriser. ${ }^{1}$ We also investigated the effect of using a hypochlorite sterilising agent during the collection procedure, since preliminary work in this department (Gibbs, unpublished observations) suggested that such simple antisepsis might influence the bacteriological outcome of pasteurisation.

\section{Methods}

The milk that drips from the opposite breast during breast-feeding is used to stock the Oxford milk bank. This drip breast milk is conveniently collected in a shell. ${ }^{1}$ During the study 60 donors contributed to the milk bank. They were allocated randomly into two groups.

Group 1-Donors in this group were issued with 120-ml plastic collecting vessels that had been washed in ordinary detergent. The donors were instructed to wash their collecting shells after each use and rinse them with tap water.

Group 2-Donors were told how to use a hypochlorite sterilising tank in which the collecting vessels, including the collecting shells, were sterilised before use.

In both groups mothers were instructed to wash their hands before handling collecting apparatus. Milk was collected in 24-hour samples, which were stored in the donors' domestic refrigerators. Every three or four days a district midwife brought the samples in a cooled container to the special-care baby unit, where the milk from each group was pooled separately. Twelve pools were studied, six from each group. Each pool comprised 75-120 24-hour collections from 25-30 donors. The pooled milk was pasteurised for 30 minutes at $62^{\circ} \mathrm{C}$ using the 